was a lawyer, inarticulate or Italian. Nor can the howlers be perpetuated that he proposed in 1811 diatomic molecules for the common elementary gases, or that he was instantly rescued from oblivion by Cannizzaro at the Karlsruhe Congress of 1860.

Of these two books Morselli's makes the more telling points because the scientific and historiographic issues have such unusual complexity and importance. But it has less relevant and fewer illustrations than its companion volume and a number of minor textual irritations. Thus Davy (whom McCosh usually calls "Humphrey") was not a single-minded supporter of contact electrification (Morselli, p. 63), nor was he a lifelong disciple of Boscovich (p. 199). Kekule was certainly not a "close friend" of Frankland (p. 233), was not called "Frederick" and did not produce the first edition of his Lehrbuch in 1867 (p. 266). Prout's Bridgewater Treatise appeared in 1834 (p. 182), not 1904 (p. 184).

It is to be hoped that future volumes in the series will benefit from more careful editorial attention. In one chapter of Morselli, for example, an article by Graebe is given no less than five different abbreviated titles, while McCosh's book is marred by an extremely high number of misprints. Other than these blemishes the main deterrent is the price. But to those who can afford them both books have much to tell of the rise of modern chemistry.

Colin Russell is Professor of History of Science and Technology at the Open University.

\section{Pieces of artificial intelligence}

Wendy G. Lehnert

Artificial Intelligence: Tools, Techniques, and Applications.

Edited by Tim O'Shea and Marc

Eisenstadt.

Harper \& Row: 1984. Pp.497. Pbk \$19, f12.95,

True to their title, C'Shea and Eisenstadt have produced an anthology of papers dealing with the tools, techniques and applications of artificial intelligence. However, while the book is intended to serve as an introduction to the field, it should not be seen as a textbook. The 15 chapters have been written by different authors and no effort has been made to achieve a unified effect, each contribution being a self-contained introduction to its own topic. As such, therefore, the book cannot be compared to single-author texts, for example Patrick Winston's Artificial Intelligence (published by Addison-Wesley in 1984), nor does it attempt to provide the comprehensive coverage of the three volumes of The Handbook of Artificial Intelligence by A. Barr, P. Cohen and E.A. Feigenbaum (Pitman, 1981 and 1982). But viewed as a collection of introductory papers, it is reasonably solid.

Here students of AI will find wellpresented material that is certain to motivate further delving into the literature. Among the topics covered are natural language, vision, robotics and expert systems, as well as introductions to the LISP and PROLOG programming languages. There is, too, an account of text processing, which really has nothing to do with AI but does show how AI techniques can be useful in spin-off applications.

There is also a chapter on how to get a $\mathrm{PhD}$ in $\mathrm{AI}$, apparently aimed at graduate students who have no adviser. As a teacher,
I found this contribution laudable in intent but irresponsible in practice. It gives the impression that a PhD in Al can be pursued by anyone with sufficient interest in the subject and access to adequate computing facilities. In fact, there are only a few computer science departments capable of supporting quality research in $\mathrm{AI}$, and all such research is conducted in the context of organized projects. Since there is a very high demand for well-qualified people in $A I$, and a paucity of such people to go around, there is a grave danger that thirdrate research will be accepted at lesser institutions for the sake of exploiting the bullish job market. A trend in this direction could hurt AI irreparably by destroying what delicate credibility has been established by more responsible research sites: a field that is as controversial and susceptible to media hype as AI cannot afford to make room for mediocre practitioners. So I fail to see how this chapter will help anyone, and I fear it will only serve to encourage borderline research.

That chapter apart, my reaction to the collection is largely positive. The various contributions grew out of a school which was aimed at both academic and industrial participants, so the book should be read in the same spirit with which one approaches a conference proceedings volume. The quality varies from paper to paper and readers are left to discover for themselves any unifying threads between topics. But given additional guidance to make more explicit the underlying principles of $\mathrm{Al}$, the book does provide a good introductory background to the field. I would therefore suggest that teachers use it as a supplementary text, or as a source of selected readings, and it should certainly be included in any library intending to keep a comprehensive collection of the AI literature.

Wendy G. Lehnert is an Associate Professor of Computer and Information Science at the University of Massachusetts.
Spasm? Or rigor?

\section{Michael Spencer}

Contractile Mechanisms in Muscle. Edited by G.H. Pollack and H. Sugi. Plenum: 1984. Pp. 921 . \$125, £106.25.

IN THE heady years of the 1960 s, D.R. Wilkie advertised a lecture on muscle with a jokey prospectus that started: "Available now. LINEAR MCTOR. Rugged and dependable: design optimized by worldwide field testing over an extended period" and ended with the laconic phrase "Good to eat". Cptimism was in the air. Nobody knew exactly what made the filaments slide, but there was no shortage of ingenious hypotheses. As few of these could immediately be tested, imaginations roamed freely; among ideas discussed were crossbridges on springs, erectile crossbridges, contractile filaments and various wheezes involving forces at a distance.

As the 1970 s dawned, the rocking crossbridge model emerged as front-runner with influential backing from the two Huxleys and others. It looked ideally suited to the simple four-stage kinetic scheme of Lymn and Taylor, with a powered change in the angle of attachment corresponding to one of the steps. It seemed inevitable that time-resolved studies by X-ray and other techniques would soon sort it all out, and Nobel-spotters made mental bets on the likely beneficiaries.

Then troubles began to mount, and nagging doubts to arise. X-ray work of ever-increasing sophistication and cost failed to reveal any obvious correlation with kinetics; and the kinetic schemes themselves became so complex that E.W. Taylor once started a lecture by observing drily that we now knew less than we did two years earlier. Worst of all, a series of new experiments with fluorescent and EPR probes failed to provide any consistent evidence that the crossbridges rocked at all. Heretics who had temporarily been silenced began to raise their voices: was the supposed mainstream of muscle research really a blind channel? At the present time few workers are sure of anything any more, and there is a desperate feeling that although no alternative scheme is highly plausible, there is some vital feature missing from the crossbridge hypothesis.

Young post-doctorals just entering the field are less afflicted by self-doubt than their more world-weary elders, and for them there is no shortage of work: many types of muscle remain almost virgin territory, and there are fascinating new techniques to spend money on. So the flow of bulky conference reports continues unabated, and the volume under review is typical: it records the second international symposium on crossbridge mechanisms and contains around half-a-million words, ending with a ruminative summary (expressing due gratitude to the organizers) 